\title{
Euratom Neutron Radiography Working Group
}

\section{Domanus, Joseph Czeslaw}

Publication date:

1986

\section{Document Version}

Publisher's PDF, also known as Version of record

Link back to DTU Orbit

\section{Citation (APA):}

Domanus, J. C. (1986). Euratom Neutron Radiography Working Group. Risø National Laboratory. Risø-M No. 2576

\section{General rights}

Copyright and moral rights for the publications made accessible in the public portal are retained by the authors and/or other copyright owners and it is a condition of accessing publications that users recognise and abide by the legal requirements associated with these rights.

- Users may download and print one copy of any publication from the public portal for the purpose of private study or research.

- You may not further distribute the material or use it for any profit-making activity or commercial gain

- You may freely distribute the URL identifying the publication in the public portal

If you believe that this document breaches copyright please contact us providing details, and we will remove access to the work immediately and investigate your claim. 
RISD-M-2576

EURATOH NEUTRON RADIOGRAPHY WORRING GROUP

J. C. Domanus

Abstract. In 1979 a Neutron Radiography Working Group (NRWG) was constituted within Euratom with the participation of all centers within the European Community at which neutron facilities were available. The main purpose of NRWG was to standardize methods and procedures used in neutron radiography of nuclear reactor fuel as well as establish standards for radiographic image quality of neutron radiographs. The NRW meets once a year in each of the neutron radiography centers to review the progress made and draw plans for the future.

Besides, ad-hoc sub-groups or. different topics within the field of neutron radiography are constituted. This paper reviews the activities and achievements of the NRWG and its sub-groups.

INIS DEscripters: EURATOM; IMAGES; IMTERNATIONAL COOPERATION; NEUTRON RADIOGRAPHY; NUCLEAR FUELS; STANDARDIZATIONJ.

Accepted for presentation at the second World Conference on Neutron Radiography, Paris, 16-20.06.1986.

April 1986

Riso National Laboratory, DK-4000 Roskilde, Denmark 
ISBN $87-550-1220-5$

ISSN 0418-6435

Grafisk Service, Riso 1986 
Conreirs

Page

1. InTRODUCTIOU ............................ 1

2. REFERELCE NEUTROA RADIOGRAPHS .................. 1

3. NEUTRON RADIOGRAPHY GAMDBOOK $\ldots \ldots \ldots \ldots \ldots \ldots \ldots \ldots \ldots \ldots .2$

4. QUALITY STANDARDS $\ldots \ldots \ldots \ldots \ldots \ldots \ldots \ldots \ldots \ldots \ldots \ldots \ldots . \ldots \ldots$

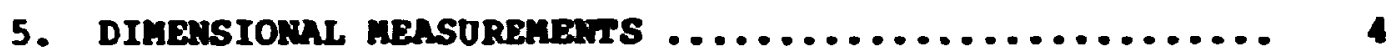

6. NRWG TEST PROGRAH $\ldots \ldots \ldots \ldots \ldots \ldots \ldots \ldots \ldots \ldots \ldots \ldots \ldots \ldots \ldots \ldots$ 5

7. RADIOGRAPHIC IMAGE QOALITY $\ldots \ldots \ldots \ldots \ldots \ldots \ldots \ldots \ldots \ldots \ldots$ 7

b. NEUTROA BENM CORPONENTS $\ldots \ldots \ldots \ldots \ldots \ldots \ldots \ldots \ldots \ldots \ldots \ldots$ 7

9. NITROCELLULOSE FILH ....................... 8

10. INTERHATIONAL MEUTRON RADIOGRAPEY MEASLETTER ...... 9

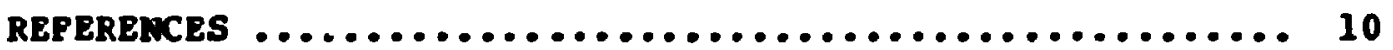





\section{INTRODUCTION}

The significance of neutron radiography (NR) for nuclear industry applications in Europe was reviewed in a previous paper III presented at the First World Conference on Neutron Radiography (San Diego, 1981). There it was explained that Industry usually adüresses requests for non-destructive testing with neutrons to the government-funded research centers. The major part of the work is carried out with research and test reactors.

Neutron radiography, like other NDT methods in the nuclear field, needs standardization in its many aspects. Unfortunate1y, very few standards relating to NDT exist in different nuclear fields $|2|$.

As many centers in the European Community perform NR of nuclear fuel it was felt that some standardization is needed in that field. Such standardization work was initiated at Risø National Laboratory, Denmark in the 70s, and in 1979 a formal Neutron Radiography Working Group (NRWG) was constituted by Euratom. In this working group all research centers of the European Community, where neutron radiography is performed, are participating (13 NR facilities in 8 centers).

The preliminary work done by NRWG was described in $|3|$. below a description is given of the main activities and achievements of the NRWG.

\section{REFERENCE NEUTRON RADIOGRAPHS}

The NRWG began its work by accepting a classification of defects occurring in light water reactor fuel, which was included in an atlas of reference neutron radiographs produced at $R i s \emptyset$ 
in 1979 |4|. This classification $|5|$ and examples of defects revealed by $N R$ were extended to $l i g h t$ water and fast reactor fuel and a special sub-group of the NRWG has produced a collection of "Reference neutron radiographs of nuclear reactor fuel", published in $1984|6|$, and described in $|7|$.

This collection provides some typical examples of nuclear fuel pins and their components. Thereafter, a classification of different findings on neutron radiographs of nuclear fuel is given. Altogether 159 neutron radiographs are reproduced. (See poster "Reference Neutron Radiographs of Nuclear Reactor Fuel").

\section{NEUTRON RADIOGRAHY HANDBOOR}

The members of the NRWG have also prepared a "Neutron radiography handbook" $|8|$ published just before the First world Conference on Neutron Radiography to which the NRWG has greatly contributed.

Now a special sub-group of the NRWG is preparing a new, revised and enlarged edition of this handbook. It is called "Practical Neutron Radiography".

\section{QUALITY STANDARDS}

Unlike the situation in other fields of industrial radiography, where standard methods and procedures are used to control the quality of the radiographic image, no such standards exist for neutron radiography of nuclear fuel. To fill that gap it was felt that standardization work ought to be started in that 
field, too. This was done by the NRWG which has initiated the search for adequate quality standards for neutron radiography of nuclear fuel $|9|$.

At the time when NRWG standardization activity was started there was only one standard published in the field of neutron radiography $|10|$. Rnowing that the ASTM standard |10| was under revision the NRWG has decided to follow the new design of the BPI and SI, which were thereafter recommended in the new issue of the ASTM standard IIII. The ASTM standard was prepared for general neutron radiography and it was felt that a specific standard is needed for neutron radiography of nuclear fuel. Therefore, the NRWG has designed a beam purity indicator almost identical as the ASTM BPI. As this BPI serves also to determine the gamma content in the neutron beam, and in neutron radiography of nuclear fuel this information is irrelevant, as the irradiated nuclear fuel itself emits a very strong gamma radiation, it was decided to design a special beam purity indicator for nuclear fuel: BPI-F.

The new design at the ASTM sensitivity indicator (SI) was also adapted by the NRWG.

All chose indicators (described in $|9|$ ) were produced at $R$ iso and distributed among all the participants of the NRWG. Even the possesion of those three indicators seemed to be insufficient for the image quality control of nuclear radiographs of nuclear fuel. Therefore, the NRWG has followed the statement of the ASTH E 545 that: "It is recognized that the only truly valid sensitivity indicator is a material or component, equivalent to the part being neutron radiographed, with a known standard discontinuity (reference standard comparison part)". Such a "reference standard comparison part" was designed by the NRWG for nuclear fuel. It was produced at Riso as a calibration fuel pin (CPP-El) and distributed among all the participants of the NRWG. It includes such "standard discontinuities" as pellet-to-pellet and pellet-to-cladding gaps (calibrated gaps from 50 to $300 \mathrm{~mm}$ ). Purther details about the CPP-El can be found both in $|9|$ and $|12|$. 
All the three indicators together with the calibration fuel pin are now being tested under a NRwG test program, described below.

It is worth mentioning that up till now 25 sets of those items were produced at $R$ isø and that they are used also in neution radiography centers outside the European Community (Israel, Japan, South Korea, Turkey, Iraq).

\section{DIMENSIONAL MEASUREMENTS}

In order to judge the behaviour of nuclear fuel pins after irradiation in a reactor, it is essential to quantitatively assess the dimensional changes occurring in the fuel itself and the cladding, and to compare this with preirradiation measurements. Neutron radiographs contain adequate information about such phenomena as swelling or cracking of the cladding or cracking or voidage formation of the fuel which can occur during irradiation. To extract this information from neutron radiographs, one must have an accurate method of measuring dimensions on the films on which neutron radiographs are taken.

A measurement of dimensions from neutron radiographs of nuclear fuel pins consists actually of measuring distances between locally occurring maxima or minima in optical film densities on the radiographs. It is consequently a length measurement. In pracice, the following dimensions are measured from neutron radiographs:

1) Outer diameter of the cladiing tube.

2) Diameter of the fuel pellet.

3) Fuel-to-clad gap.

4) Cladding tube wall thickness.

5) Pellet length.

6) Pellet-to-pellet gap. 
7) Dishing in the pellet.

8) Fuel column length.

other dimensions can also be of interest, e.g. the central void diameter and length, the crack width in the pellets and many other.

Although it is comparatively easy to see even minute changes in dimensions on neutron radiographs, it is very difficult to measure them accurately. This problem was investigated at Risø $|13|$ using different measuring techniques and is now under investigation by the NRWG.

The folowing devices and methods have been reported for dimensional measurements: travelling microscope and light table micrometer, optical projector, travelling microdensitometer, photographic enlargement, sharpening and image enhancement, electronic image processing. In practice two instruments are suitable for that purpose: the optical projector and the travelling microdensitometer. They are both described in $|14|$.

The underlying physical processes and mathematical methods used for dimensional measurements were treated in numerous publications e.g. |15|. A special book on that subject was recently published. $|16|$

6. NRWG TEST PROGRAM

The NRWG has developed a test program for checking the image quality and accuracy of dimensions measured from neutron radiographs of nuclear fuel pins 117,181 . For that program indicators described above (BPI, BPI-P, SI) and calibration fuel pin (CPP-EI) are used. They are neutron radiographed together at each of the NR facilities participating in the NRWG. Silver halide $x-r$ ay films are exposed with Gd and Dy converters by the 
NRWG TEST PROGRAM

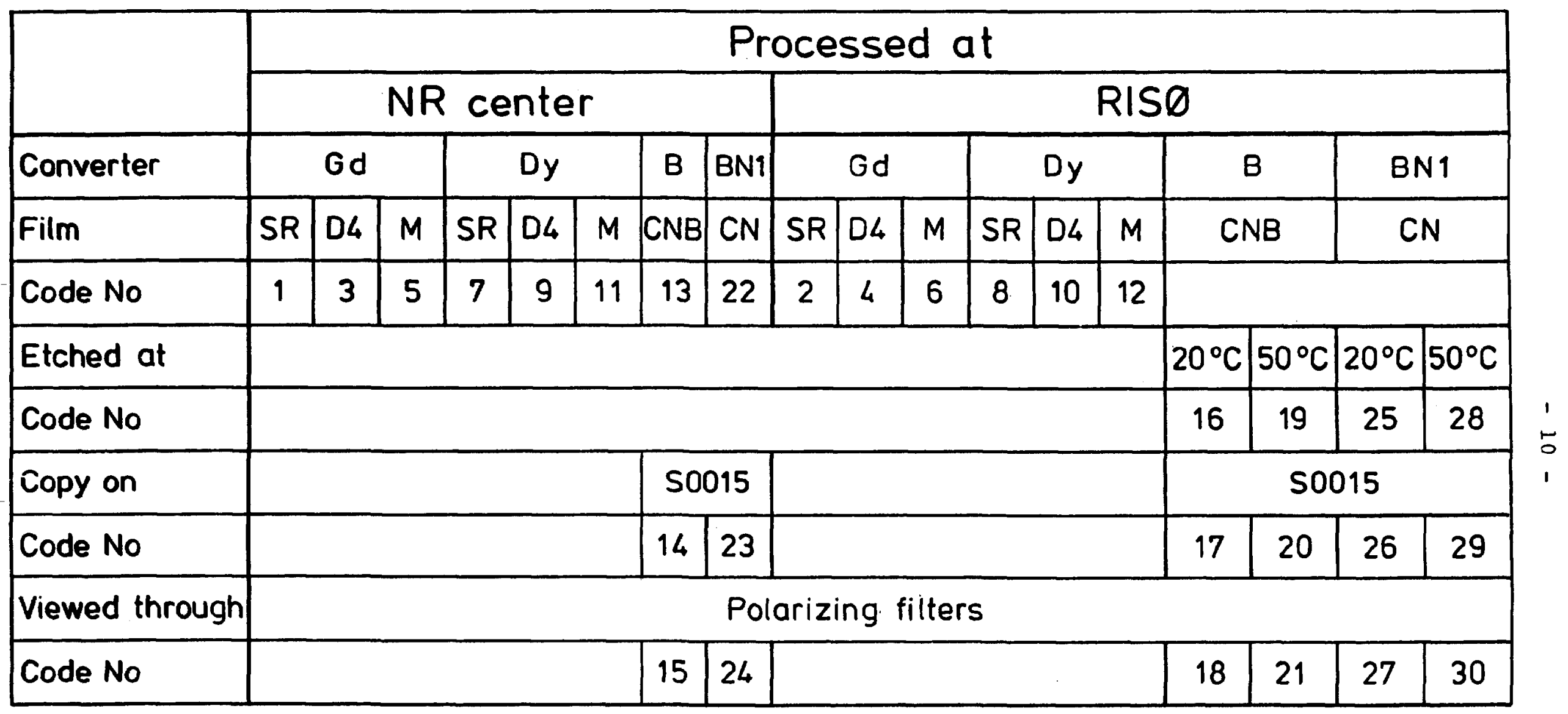

Fig. 1. NRWG Test Program 
direct and transfer method. Nitrocellulose film coated on both sides with a converter and without coating but between two converter screens, are alsu used. The radiographs are thereafter processed at the centers themselves and another set of identical radiographs centrally at Risø.

Altogether 30 visual evaluations, film density and dimensional measurements are being done for each set of neutron radiographs taken at each NR facility. (See fig. 1 ).

From the radiographs of the BPI and BPI-F neutron beam constituents will be calculated. The sensitivity levels are found from the SI and from the CFP-El the image quality and accuracy of dimensional measurements are determined. The results of those measurements will be compared and conclusions drawn about the suitability of the test items for the purpose of controlling the quality of neutron radiographs of nuclear reactor fuel.

7. RADIOGRAPHIC IMAGE QUALITY

As stated in the ASTM standard |1II: "The judgement of the quality of a neutron radiograph is based upon the evaluation of images obtained from indicators that are exposed along with the test object". Such indicators (BPI, BPI-F, SI, CFP-El, are presently tested under the NRWG Test Program.

Although the Test Program is not finished yet, some preiiminary conclusions were drawn already from the results available up $t i l l$ now. They can be found in $|19,20,21|$.

The problem of the usefulness of the SI for the assessment of radiographic image quality was further treated in $|23|$, presented at this conference. 
Another approach to the assessment of radiographic image quality by visual examination of neutron radiographs of the calibration fuel pin was described in $|24|$, presented at this conference.

8. NUCLEAR BEAM COMPONENTS

The ASTM standard IIll describes the purpose of using of the beam purity indicato: in the following way (\$3.1): "The BPI is designed to yield information concerning neutron beam and image system parameters that contribute to film exposure and thereby affect overall image quality. In addition the beam purity indicator can be used to verify the day-to-day consistency of neutron radiographic quality". Furthermore formulas are given in the standard to calculate neutron beam constituents from density measurements of the BPI. Similar formulas are given for the NRWG BPI-F in $|18|$.

According to those formulas nuclear beam components are calculated for all $30 \mathrm{film} /$ converter combinations (see fig. 1) for each NR facility participating in the NRWG Test Program. Those results will be furthermore used to assess usefulness of the beam purity indicators.

The conclusions about the usefulness of the beam purity indicators will be first formulated after the termination of the NRWG Test Program las is the case for the radiographic image quality).

Also here some preliminary conclusions were drawn from the Test Program results available till now. They can be found in 119 , $20,21 \mid$ and $|22|$.

This subject is also treated in $|23|$ piesented at this conference. 


\section{NITROCELLULOSE FILH}

The use of nitrocellulose film for neutron radiography of irradiated nuclear fuel is steadily increasing. The advantages of the track-etch over the transfer method can expiain this.

In Europe several NR facilities, where post-irradiation examination of nuclear fuel is done by neutron radiography, perform this control exclusively using the nitrocellulose film. Here the Service des Piles of the French center in Saclay as well as the Joint kesearch Centre at Petten, Holland, can serve as an example.

There are many factors that govern the correct exposure of nitrocellulose film. To obtain the best radiographic image quality one must choose optimum conditions for exposing the nitrocellulose film to neutrons (neutron fluence) as well as optimum conditions for etching letching solution and its concentration, etching time and temperature). All those factors are under examination at several NR centers. The most extensive research in that field is done at Saclay, France, where experiments were done with $\mathrm{NaOH}$ and $\mathrm{KOH}$ as etching agents and different converter screens used with the Kodak-Pathe CN85 nitrocellulose film. The results were described in $|25|$ and $|26|$. According to R. Barbalat $|27|$ one can adopt as a rule of thumb that an underirradiation followed by an overetching will give improved sensitivity and contrast, whereas an overirradiation and underetching produces an image of lowered contrast but richer in detail.

A similar investigation as at Saclay is being also made at Petten, Holland, now $|28|$.

At Riso a comparison was made of radiographic image quality and sensitivity of neutron radiographs taken on silver halide and nitrocellulose film 129,301 . A more extensive comparifon of that kind will soon be possible when all results from the NRWG test program will be available. 
A sub-group on nitrccellulose film of the NRW is currently preparing a special report on the use of nitrocellulose film in neutron radiography. The results from this report will thereafter be included in "Practical Neutron Radiography" handbook (see above).

10. INTERNATIONAL NEUTRON RADIOGRAPHY NEWSLETTER

To keep all concerned informed about the activities of different centers and organizations in the field of NR an "Interrational Neutron Radiography Newsletter" (INRNL) is published (editor, J. C. Domanus) in English in the British Journal of Non-Destructive Testing and in French in the Revue Pratique de Control Industriel. It is the continuation of the previous Neutron Radiography Newsletter, edited by J. P. Barton and published by the ASNT (J. P. Barton is co-editor for America of the present INRNL).

REFERENCES

III J. C. Domanus \& P. von der Hardt. Nuclear industry application of neutron radiograpiny in Europe, 35-46 in Proceedings of the lst WCNR.

I2I J. C. Domanus, Editorial. Nuclear Europe. Vol.4, No.11, November 1984, p.11.

$|3|$ J. C. Domanus. Standardization activities of the Euratom Neutro.n Radiography Working Group. Risø-M2356. June 1982 . 
I4I J. C. Domanus. Neutron radiographic findings in light water reactor fuel. Metallurgy Department, Riso National Laboratory. June 1979.

I5I J. C. Domanus. First attempt to classify defects revealed by neutron radiography in nuclear fuel for light water reactors. Risø-M-2171. April 1979.

$16 \mid$ J. C. Domanus (editor). Reference neutron radiographs of nuclear reactor fuel. D. Reidel Publishing Company. 1984 .

I7I J. C. Domanus. Neutron radiographic findings in reactor fuel. Proceedings of the $6 \mathrm{th}$ ASM International Conference on NDE in the Nuclear Industry, zorich, Switzerland. 28.11-2.12.1983, pp 453-460.

|8| P. von der Hardt H. Rottger. (eds.) Neutron radiographỵ handbook. D. Reidel Publishing Company. 1981.

191 J. C. Domanus. Search for adequate quality standards for neutron radiography of nuclear fuel: 1017-1024 in Proceedings of the lst WCNR.

|10| ASTM E 545-75. Standard method for determining image quality in thermal neutron radicgraphic testing.

I11I ASTM E 545-81.

1121 J. C. Domanus. Calibration fuel pin CFP-El. Risø Report B-499. Metallurgy Department, Risø National Laboratory. February 1981.

$|13|$ J. C. Domanus. Accuracy of dimension measurements from neutron radiographs of nuclear fuel pins. RisoM-1860. March 1976.

$|14|$ J. C. Domanus. Euratom work on standard defects and dimensional measurements in neutron radiography of nuclear fuel elements. Risø-M-2318. October 1981. 
|15| A. A. Harms. Physical processes and mathematical methoōs in neutron radiography. Atomic Energy Review. Vo1. 15, No. 2. June 1977, 143-168.

I16i A. A. Harms \& D. R. Wyman. Mathematics and physics of neutron radiography. D. Reidel Publishing Company.

|17| J. C. Domanus. Euratom test program for inage quality and accuracy of dimensions. 1025-1033 in Proceedings of the lst WCNR

$|18|$ J. C. Domanus. Revised test program for testing of the CFP-El; ASTM (revised) BPI and SI and BPI-F. Riso Report B-512. Metallurgy Department. Riso National Laboratory. August 1981.

$119 \mid$ A. Laporte G. Bayon. Determination of image quality in industrial neutron radiography. CEN-FAR. Service des Piles de Saclay - Section d'exploatation TRITON. 6.203 .2 .

$120 \mathrm{I}$ J. C. Domanus. Control of radiographic image quality in neutron radiography of nuclear fuel. Proceedings of the 6 th ASM International Conference on NDE in the Nuclear Industry. Zarich, Switzerland. 28.11.$2.12 .1983,447-451$.

121 J. C. Domanus, P. Gade-Nielsen J. Olsen. How good are the standards for the image quality control in neutron radiography of nuclear fuel? Proceedings of the 7 th International Conference on NDE in the Nuclear Industry. Grenoble, France. 29.1-1.2.1985. 325328.

122 J. C. Domanus. Activities and achievements of the Euratom Neutron Radiography Working Group. Materials Evaluation, Vo1. 44, No 1, January 1986, 114-119. 
I23| J. C. Domanus. Can neutron bean conponents and adiographic inage quality be determined by the use of bean purity and sensitivity indicators? Proceedings of the 2nd WCNDT.

I24I J. C. Domanus. Assessment of radiographic inage quality by visual examinaticn of neutron radiographs of the calibration fuel pin. Proceedings of the 2 nd WCNR.

|25| R. Barbalat. Utilisation de l'installation de neutronographie sur materiaux radioactifs en service sur le reacteur ISIS ou CEN/Saclay. Mise en oeuvre et exploatation de la nitrocellulose en neutronographie. CEA. CONF. 5736. Paper prepared for the kRWG meeting at Grenoble. 2-3.6.1981.

I26I R. Barbalat. Use of cellulose nitrate for neutron radiographic testing of burned fuel elements. 747-753 in Proceedings of the 1st WCKR.

|27| R. Barbalat in EUR report: "Neutron radiography on nitrocellulose film" (to be published in 1986).

| $28 \mid$ H. P. Leeflang. Private communication.

$129 \mid$ J. C. Domanus. Comparison of image quality of nuclear fuel neutron radiographs taken on silver halide and nitrocellulose film. Risø-M-2170. April 1979.

| $30 \mid$ J. C. Domanus. How good is nitrocellulose film for neutron radiography? $729-736$ in Proceedings of the lot WCNR. 
J. C. Domanus

\section{7 if pages + tables + 1 illustrations}

Abstract

In 1979 a Neutron Radiography Working Group (NRWG) was constituted within Euratom with the participation of all centers within the European Community at which neutron facilities were available. The main purpose of NRWG was to standardize methods and procedures used in neutron radiography of nuclear reactor fuel as well as establish standards for radiographic image quality of neutron radiographs. The NRWG meets once a year in each of the neutron radiography centers to review the progress made and draw plans for the future.

Besides, ad-hoc sub-groups on different topics within the field of neutron radiograpi.y are constituted. This paper reviews the activities and achievements of the NRWG and its sub-groups.

Accepted for presentation at the Second World Conference on Neutron Radiography, Paris. $16-20.06 .1986$

Availajle on request from Rise Library, Ris National Laboratory (Ri Bibliotek), Poresgsanlag Risø), DK-400O Roskilde, Denmark

Telephone: (02) 371212 , ext. 2262. Telex: 43116 